\begin{tabular}{|c|l|}
\hline Title & Diet and birdsong : short-term nutritional enrichment improves songs of adult Bengal ese finch mal es \\
\hline Author(s) & Y amada, Kentaro; Soma, Masayo \\
\hline Citation & $\begin{array}{l}\text { Journal of Avian Biology, 47(6), 865-870 } \\
\text { https://doi.org/10.1111ßav.00979 }\end{array}$ \\
\hline Issue Date & 2016-12 \\
\hline Doc URL & http://hdl.handle.net/2115/67763 \\
\hline Rights & The definitive version is available at www.blackwell-synergy.com \\
\hline Type & article (author version) \\
\hline File Information & Yamada\& Soma2016.pdf \\
\hline
\end{tabular}

Instructions for use 


\title{
Diet and birdsong: short-term nutritional enrichment improves songs of adult Bengalese finch males
}

\author{
Kentaro Yamada and Masayo Soma* \\ *masayo.soma@sci.hokudai.ac.jp, \\ Hokkaido Univ., Hokkaido, Japan.
}

Song is a notable sexual signal of birds, and serves as an honest indicator of male quality. Condition dependence of birdsong has been well examined from the viewpoint of the developmental stress hypothesis, which posits that complex songs assure fitness because learned acoustic features of songs are especially susceptible to early-life stress that young birds experience in song learning periods. The effect of early stress on song phenotypes should be crucial, especially in age-limited song learners which sing stereotyped songs throughout life. However, little attention has been paid to non-learned song features that can change plastically even in adulthood of age-limited song-learners. Although it has been shown that food availability affects song rate in wild songbirds, there is limited evidence of the link between favorable nutritional conditions and song phenotypes other than song rate. Under the prediction that singing behavior reflects an individual ' $s$ recent life history, we kept adult Bengalese finch males under high-nutrition or normal diet for a short term, and examined changes in body mass and songs. We found that birds on a high-nutrition diet showed higher song output (e.g. song rate and length) compared with those of the control group, while changes in body mass were moderate. In addition, note repertoire became more consistent and temporal structures got faster in both nutrition and control groups, which indicates that songs were subject to other factors than nutrition. Considering that female estrildid finches, including Bengalese and zebra finches, show a preference toward complex songs as well as longer songs and higher song rate, it is plausible that different aspects of singing behavior signal different male qualities, and provide multifaceted clues to females that choose mates.

Birdsong is a sexual signal that serves as an indicator of male quality (Catchpole and Slater 2008). Ever since the nutritional stress hypothesis was proposed (Nowicki et al. 1998), a number of studies have tried to show that song quality of individuals reflects early life history experiences such as developmental or nutritional stress (reviewed by Spencer and MacDougall-Shackleton 2011, Buchanan et al. 2013). Such findings have contributed to our understanding of why the song of oscine males serves as an honest signal in mate choice (Gil and Gahr 2002). In close-ended song learners like the well-studied zebra finch (Taeniopygia guttata) and Bengalese finch (Lonchura striata var. domestica), learned acoustic features of songs, such as note type repertoire, crystalize and show little change after the song learning period, and hence are susceptible to early-life stress that affects neural development during this critical period (e.g. Spencer et al. 2003, Soma et al. 2006, Holveck et al. 2008, Zann and Cash 2008, Brumm et al. 2009; reviewed by Riebel 2009).

In contrast, recent studies highlighted that temporal aspects of songs show some plasticity in later life even after song crystallization in estrildid finches: Java sparrows (Lonchura oryzivora) and Bengalese finches show age-related increases in song tempo or length (James and Sakata 2014, Ota and Soma 2014). In addition, song output (i.e. song rate, and amplitude) is subject to adulthood conditions (e.g. food availability, Rashotte et al. 2001, Johnson and Rashotte 2002, Lynn et al. 2010, Ritschard and Brumm 2012; parasite load, Møller 1991). Hence, we assume that individual differences in both song output (e.g. song rate and length) and vocal performance (e.g. tempo) should be variable to some degree, reflecting more recent life history, mediated by current physical conditions. This notion is indirectly supported by previous findings that showed an association between body size and song output or vocal performance in several estrildid finches (Soma et al. 2006, Kagawa and Soma 2013, but also see Brumm 2009, Van Hout et al. 2012).

In general, physical condition responds sensitively to food availability and energy expenditure, which is a factor that affects singing in songbirds (cf. Van Hout et al. 2012). In wild populations of insectivorous songbirds that are expected to live in energetically challenging conditions, supplemental feeding increased body mass and song rate (e.g. Reid 1987, Alatalo et al. 1990, Cuthill and Macdonald 1990, Cucco \& Malacarne 1997, Berg et al. 2005, Barnett and 
Briskie 2007), while unpredictable feeding schedules negatively affected singing activity (Thomas 1999, see also Lucas et al. 1999). In a domesticated songbird, restricted food access had a negative effect on song rate and amplitude (Ritschard and Brumm 2012).

The question yet to be answered is whether song output and vocal performance improves even when captive and domesticated well-fed birds experience better nutritional conditions and gain weight in adulthood. To our knowledge, this has not been tested because domesticated birds are thought to live close to the upper limit of energy intake with abundant food. However, this question concerns song plasticity, and is of particular importance when trying to answer how much individuals can potentially compensate for the deficits caused by early stress by later favorable conditions (Metcalfe and Monaghan 2001). To test this, we kept adult Bengalese finch males under high-nutrition or normal diet for a short term, and examined the changes in body mass and singing.

\section{Methods}

We used a total of 19 adult male Bengalese finches, which were from a laboratory population $(\mathrm{n}=3,1.3$ year-old siblings without breeding experience) or purchased from local pet suppliers $(\mathrm{n}=16$, unknown age and breeding experience). Usually, Bengalese finches are fully sexually mature and have crystallized song when they are $>0.5$ years old. They were assigned to either a nutrition $(n=10)$ or a control group $(n=9)$ pseudo-randomly to balance body weights between the two groups. As a result body weight was not significantly different between the two groups ( $t$-test: $t=0.12, p=0.90$, see also Fig. 2i) before the experiment. The subjects were kept under control/nutrition food treatment for 40 days. This experimental period was set based on a field observations of the wild strain, white-rumped munias Lonhura striata, whose breeding seasonality is determined by rice cultivation; birds opportunistically eat protein-rich algae for 1-2 months during the pre-breeding period (Avery 1980).

In the control group, birds were fed with standard maintenance food that contained finch seed mixture (6:3:1 mix of Japanese millet, foxtail millet, and millet), shell grit, and dried green vegetable food, while experimental group birds were additionally supplied with a high nutrition diet that is usually given to breeding pairs $(1: 1: 1$ mix of rice, canary seed, and hand-made egg yolk-coated millet). Specifically, the egg yolk-coated millet was crumbed with a mixture of salt, TetraMin (Tetra, Germany; tropical fish food), dried crucian powder, honey, powdered milk, and soy bean flour, based on the recipe of Bengalese finch breeders (Supplementary Table S1). As Bengalese finches have a highly gregarious nature (Goodwin 1982), we did not cage them individually in order not to induce isolation stress. To minimize competition for food during the experimental period, we kept four or five individuals of the same experimental group in each cage $(34 \times 34 \times 39 \mathrm{~cm})$, equipped with a water bowl and a greater number of bigger food bowls than before the experiment started. Specifically, three semicircular bowls (dia. $11 \times 5 \mathrm{~cm})$ contained the above food, which allowed all cage mates to forage simultaneously. Subject birds had ad libitum food access, all food was replenished on a daily basis well before each food cup became empty.

To confirm that above menu in the nutrition group was nourishing, nutritional ingredients of their diet were estimated based on the proportion of intake (i.e. pecking times for each food), the nutrition facts of each product, and the Japanese Standard of Dietic Information (Supplementary Table S1, 2). Shell grit was not included in this dietary analysis because we could not obtain its exact nutritional value but assumed that shell grit is mostly composed of calcium carbonate that is independent of the ingredients examined in Table S2.

Before and after the experimental period, subjects were weighed using a digital balance, and then introduced individually to a small cage $(15 \times 20 \times 30 \mathrm{~cm})$ placed in a sound-attenuated box to record songs. Songs were recorded with a digital audio recorder (Marantz, PMD661) for 24 hours running from17:00 to 17:00 the next day, though birds showed no activity during the dark period (20:00-8:00). From the recording, we took the following song output variables (a-c): song rate measured as total number of songs sung during recording; and song length measured as duration of each song bout ( $\mathrm{sec}$ ) and total number of notes included in each song. We also measured vocal performance (d-f): tempo measured as the number of notes per song bout $(/ \mathrm{sec})$; and durations of all song notes (sec) and note-to-note intervals $(\mathrm{sec})$ included in songs. Additionally, we measured two aspects of song complexity ( $\mathrm{g}$, h): total note repertoire that each bird had, and note repertoire consistency, for comparing them with the above song measures. Songs of the Bengalese finch include around 20 to several hundreds of notes in total that are a repetition of about 6-11 note types (cf. Soma et al. 2009). Therefore, total note repertoire that each bird has is independent of the total number of notes, measured as an index of song length. Note repertoire consistency was the proportion of note repertoire sung in each song to the total note repertoire that each subject had. Although Bengalese finches are known to sing stereotyped 
songs with the same set of note types, they can sometimes fail to include the entire note repertoire in a song, and may miss one or two note types.

Because we expected increases in song measurements and body weight after the experimental period particularly in the nutrition group, we focused on the effects of the interaction between the experimental group (control/nutrition) and period (before/after). In particular, we entered the effects of the experimental group, experimental period and their interaction as explanatory variables in the models described below, and examined if their coefficients were statistically significantly different from 0 . All statistical tests were two-tailed and $\alpha$ was set to 0.05 . We adopted a GLMM with a Poisson distribution for the analysis of song rate and total number of notes, and total note repertoire, and a LME model for the analysis of the rest of the variables. In all these models, we considered subject identity and cage identity as nested random effects to deal with non-independence of the data from the same individual or from the same cage environment.

We used Avisoft SAS Lab pro for acoustic analyses, and R 3.1.3 for statistical analyses.

\section{Results}

\section{(a) Nutritional ingredients}

The diet of the nutrition group contained a higher amount of protein, fat, and Vitamin D, E, and B1, but not carbohydrate, phosphorus or Vitamin A (Supplementary Table S2, Fig. 1). Calorific content was slightly, but statistically significantly higher, for the diet of the nutrition group (Supplementary Table S2, Fig. 1).

\section{(b) Body mass changes after the experimental period}

Change in body mass was not statistically significant in both control and nutrition groups (Table 1i), but a marginally significant effect of the interaction $(\mathrm{p}=0.077)$ indicates that birds in the nutrition group tended to gain more body mass (Fig. 2i).

\section{(c) Song changes after the experimental period}

\section{Song output}

Song rate and total number of notes per song increased significantly after the experimental period, and the significant interactions between the experimental period and group indicate that those in the nutrition group increased more than the control group (Table 1a, c, Fig. 2a, c). Although there were no statistically significant changes in song duration between before and after the experimental period, a significant interaction between the experimental period and and group means that song duration increased only in the nutrition group (Table 1b, Fig. 2b).

\section{Vocal performance}

Tempo increased significantly after the experimental period, but a significant negative interaction between the experimental period and group indicates that the increase was larger for birds in the control group (Table 1d, Fig. 2d). This was related to the differences in tempo that already existed between control and nutrition groups before the experiment (Fig. 2d). As tempo increased proportionally in both groups, the changes were larger for control group that had higher tempo. To confirm this, we repeated the above analysis using the data on $\%$ changes in tempo and found that the experimental period but not the interaction had significant effect (experimental period: $\mathrm{p}<0.015$, interaction: $\mathrm{p}=$ 0.154). Such change in tempo was partially consistent with the other two temporal parameters, note duration and note-to-note interval, as they became shorter after the experimental period regardless of experimental group (Table 1e, f, Fig. 2e, f).

\section{Song complexity}

As expected, total note repertoire, a learned song trait, did not change after the experimental period in both control and nutrition groups (Table 1h, Fig. 2g). However, note repertoire consistency became higher after the experimental period irrespective of experimental group (Table 1i), which indicates that the birds after the experiment tended to sing songs with their full note repertoire. 


\section{Discussion}

We show that nutritional conditions experienced in adulthood influence singing behaviors. Song rate and length increased in the nutrition group after food treatment, which indicates that dietary nutritional during the experiment played a role. In addition, note repertoire became more consistent and temporal structures got faster in the nutrition and control groups, which was possibly caused by enhanced food availability during the experiment, or any other unlooked factors. Overall, these results support the idea that songs serve as a condition dependent sexual signal, which conforms to the predictions of the developmental stress hypothesis (Nowicki et al. 1998), but extends its scope from early to whole life history. In particular, while it has been shown that early stress leaves irreversible deficits on neural development that reflect into learned song phenotypes (reviewed by Spencer and MacDougall-Shackleton 2011, Buchanan et al. 2013), it is clear from our results that favorable conditions in later life also affect non-learned song traits to some degree. This means that songs signal both past and present conditions, and provide multifaceted clues to females that choose mates.

Estrildid females are reported to show a preference toward complex songs, as well as longer songs and a higher song rate (e.g. Clayton and Pröve 1989, Collins et al. 1994, Neubauer 1999, Morisaka et al. 2008, Riebel 2009, Soma and Okanoya 2013), while Bengalese finch females can be heterogeneous in preference for song complexity, with some preferring variable songs and others preferring stereotypic directed songs (Morisaka et al. 2008, Dunning et al. 2014, also see Kato et al. 2010). Considering that the songs were undirected in this study, it is possible that higher song output (song rate and length) might be beneficial for males as it could increase their chances of being heard by females, or improve their vocal performance through motor training. Observed changes in vocal performance (i.e. faster songs after the experiment) could be an outcome of such motor training, but it cannot explain why both nutrition and control groups showed similar increase in vocal performance.

Our result is in accord with previous studies on animals from various taxonomic groups, that have shown that nutritional enrichment is responsible for up-regulated expression of sexual traits, such as ornamental feather color in the house finch Carpodacus mexicanus (Hill 2000), courtship intensity in wolf spiders Pardosa prativaga (Lomborg and Toft 2009), and chemical signals in Iberian rock lizards Lacerta monticola (Martín and López 2006). Moreover, experimentally increased food availability contributes to song rate in wild songbirds (Reid 1987, Alatalo et al. 1990, Cuthill and Macdonald 1990, Cucco \& Malacarne 1997, Berg et al. 2005, Barnett and Briskie 2007). Considering that changes in song rate and length were marked in the nutrition group in our study, not only food availability but also nutritional ingredients could be factors that affect singing behavior. However, there is little evidence on how particular nutritional components affect birdsong except for a correlational study (Van Hout et al. 2012), and an experimental study of the European starling (Sturnus vulgaris), in which administration of an antioxidant (i.e. lutein) increased song rate (Casagrande et al. 2014). The finding in the European starling, and our finding, are in accord on the positive nutritional effect on song rate, while the diet in our study was rich not only with antioxidants (i.e. vitamin E), but also with calories, protein and fat (Fig. 1), which was intended to simulate diet changes during breeding (Ankney and Scott 1980, Avery 1980). The nutritional boosting effect on songs has not only been observed in wild-caught birds (Casagrande et al. 2014), but also in the captive domesticated strain (our study), even though the latter is assumed to be well fed. This means that singing behavior has a greater potential plasticity than we can usually observe.

Overall, our results highlighted the condition-dependence of birdsong. Together with past research on the developmental stress hypothesis, we assume that songbirds with a poor start can compensate to some degree with regard to the intensity of their singing performance. Even though this study is based on captive domesticated birds that may not have experienced starvation, parent-offspring conflict and sibling competition is a plausible causal factor for a poor start in early life in the wild and captivity. Because of the trade-off between current and future reproduction, parental provisioning may not fulfill the need of offspring (Trivers 1974), which should cause food competition among siblings (cf. Soma et al. 2007). As compensation growth often accompanies various costs (Metcalfe and Monaghan 2001), it is likely that early developmental stress on song traits would not be fully compensated. Future studies should address singing behaviors expressed as the interaction between past and present conditions.

\section{Acknowledgement}

This study was supported by the JSPS Grants-in-Aid for Young Scientists (23680027) to MS. 


\section{References}

Alatalo, R. V., Glynn, C. and Lundberg, A. 1990. Singing rate and female attraction in the pied flycatcher: an experiment. - Anim. Behav. 39: 601-603.

Ankney, C. D. and Scott, D. M. 1980. Changes in nutrient reserves and diet of breeding brown-headed cowbirds. - Auk 97: 684-696.

Avery, M. L. 1980. Diet and breeding seasonality among a population of sharp-tailed munias, Lonchura striata, in Malaysis. - Auk 97: 160-166.

Barnett, C. A., and Briskie, J. V. 2007. Energetic state and the performance of dawn chorus in silvereyes (Zosterops lateralis). - Behav. Ecol. Sociobiol. 61: 579-587.

Berg, M. L., Beintema, N. H., Welbergen, J. A., and Komdeur, J. 2005. Singing as a handicap: the effects of food availability and weather on song output in the Australian reed warbler Acrocephalus australis. - J. Avian Biol. 36: 102-109.

Brumm, H. 2009. Song amplitude and body size in birds. - Behav. Ecol. Sociobiol. 63: 1157-1165.

Brumm, H., Zollinger, S. A. and Slater, P. J. B. 2009. Developmental stress affects song learning but not song complexity and vocal amplitude in zebra finches. - Behav. Ecol. Sociobiol. 63: 1387-1395.

Buchanan, K. L., Grindstaff, J. L. and Pravosudov, V. V. 2013. Condition dependence, developmental plasticity, and cognition: implications for ecology and evolution. - Trends Ecol. Evol. 28: 290-296.

Casagrande, S., Pinxten, R., Zaid, E. and Eens, M. 2014. Carotenoids, birdsong and oxidative status: administration of dietary lutein is associated with an increase in song rate and circulating antioxidants (albumin and cholesterol) and a decrease in oxidative damage. - PLoS One 9: e115899.

Catchpole, C. K. and Slater, P. J. B. 2008. Bird song: biological themes and variations. - Cambridge Univ. Press.

Clayton, N. and Pröve, E. 1989. Song discrimination in female zebra finches and Bengalese finches. - Anim. Behav. 38: 352-353.

Collins, S. A., Hubbard C. and Houtman, A. M. 1994. Female mate choice in the zebra finch - the effect of male beak colour and male song. - Behav. Ecol. Sociobiol. 35: 21-25.

Cucco, M. and Malacarne, G. 1997. The effect of supplemental food on time budget and body condition in the black redstart Phoenicurus ochruros. - Ardea 85: 211-221.

Cuthill, I. C. and Macdonald, W. A. 1990. Experimental manipulation of the dawn and dusk chorus in the blackbird Turdus merula. - Behav. Ecol. Sociobiol. 26: 209-216.

Dunning, J. L., Pant, S., Bass, A. Coburn, Z. and Prather, J. F. 2014. Mate choice in adult female Bengalese finches: females express consistent preferences for individual males and prefer female-directed song performances. PLoS One 9: e89438.

Gil, D. and Gahr, M. 2002. The honesty of bird song: multiple constraints for multiple traits. - Trends Ecol. Evol. 17: 133-141.

Goodwin, D. 1982. Estrildid finches of the World. - Cornell University Press.

Hill, G. E. 2000. Energetic constraints on expression of carotenoid-based plumage coloration. - J. Avian Biol. 31: 559566.

Holveck, M. J., de Castro, A. C. V., Lachlan, R. F., ten Cate, C. and Riebel, K. 2008. Accuracy of song syntax learning and singing consistency signal early condition in zebra finches. - Behav. Ecol. 19: 1267-1281.

James, L. S. and Sakata, J. T. 2015. Vocal motor changes beyond the sensitive period for song plasticity. - J. Neurophysiol. 112: 2040-2052.

Johnson, F. and Rashotte, M. E. 2002. Food availability but not cold ambient temperature affects undirected singing in adult male zebra finches. - Physiol. Behav. 76: 9-20.

Kagawa, H. and Soma, M. 2013. Song performance and elaboration as potential indicators of male quality in Java sparrows. - Behav. Process. 99: 138-144.

Kato, Y., Hasegawa, T. and Okanoya, K. 2010. Song preference of female Bengalese finches as measured by operant conditioning. - J. Ethol. 28: 447-453.

Lomborg, J. P. and Toft, S. 2009. Nutritional enrichment increases courtship intensity and improves mating success in male spiders. - Behav. Ecol. 20: 700-708.

Lucas, J. R., Schraeder, A. and Jackson, C. 1999. Carolina chickadee (Aves, Paridae, Poecile carolinensis) vocalization rates: effects of body mass and food availability under aviary conditions. - Ethology 105: 503-520. 
Lynn, S. E., Stamplis T. B., Barrington, W. T., Weida, N. and Hudak, C. A. 2010. Food, stress, and reproduction: short-term fasting alters endocrine physiology and reproductive behavior in the zebra finch. - Horm. Behav. 58: 214-222.

Martín, J. and López, P. 2006. Vitamin D supplementation increases the attractiveness of males' scent for female Iberian rock lizards. - Proc. R. Soc. B 273: 2619-2624.

Metcalfe, N. B. and Monaghan, P. 2001. Compensation for a bad start: grow now, pay later? - Trends Ecol. Evol. 16: 254-260.

Møller, A. P. 1991. Parasite load reduces song output in a passerine bird. - Anim Behav. 41: 723-730.

Morisaka, T., Katahira, K. and Okanoya, K. 2008. Variability in preference for conspecific songs with syntactical complexity in female Bengalese Finches: towards an understanding of song evolution. - Ornithol. Sci. 7: 7584.

Neubauer, R. L. 1999. Super-normal length song preferences of female zebra finches (Taeniopygia guttata) and a theory of the evolution of bird song. - Evol. Ecol. 13: 365-380.

Nowicki, S., Peters, S. and Podos, J. 1998. Song learning, early nutrition and sexual selection in songbirds. - Am. Zool. 38: 179-190.

Ota, N. and Soma, M. 2014. Age-dependent song changes in a closed-ended vocal learner: elevation of song performance after song crystallization. - J. Avian Biol. 45: 566-573.

Rashotte, M. E., Sedunova, E. V., Johnson, F. and Pastukhov, I. F. 2001. Influence of food and water availability on undirected singing and energetic status in adult male zebra finches (Taeniopygia guttata). - Horm. Behav. 74: 533-541.

Reid, M. L. 1987. Costliness and reliability in the singing vigour of Ipswich sparrows. - Anim. Behav. 35: $1735-1743$.

Riebel, K. 2009. Song and female mate choice in zebra finches: a review. - Adv. Stud. Behav. 40: 197-238.

Ritschard, M. and Brumm, H. 2012. Zebra finch song reflects current food availability. - Evol. Ecol. 26: 801-812.

Soma, M., Saito, D. S., Hasegawa, T. and Okanoya, K. 2007. Sex-specific maternal effect on egg mass, laying order, and sibling competition in the Bengalese finch (Lonchura striata var. domestica). - Behav. Ecol. Sociobiol. 61:1695-1705.

Soma, M., Hiraiwa-Hasegawa, M. and Okanoya, K. 2009. Song-learning strategies in the Bengalese finch: do chicks choose tutors based on song complexity? - Anim. Behav. 78: 1107-1113.

Soma, M. and Okanoya, K. 2013. Differential allocation in relation to mate song quality in the Bengalese finch. Behaviour 150: 1491-1508.

Soma, M., Takahasi, M., Ikebuchi, M., Yamada, H., Suzuki, M., Hasegawa, T. and Okanoya, K. 2006, Early rearing conditions affect the development of body size and song in Bengalese finches. - Ethology 112: 1071-1078.

Spencer, K. A., Buchanan, K. L., Goldsmith, A. R. and Catchpole, C. K. 2003. Song as an honest signal of developmental stress in the zebra finch (Taeniopygia guttata). - Horm. Behav. 44: 132-139.

Spencer, K. A. and MacDougall-Shackleton, S. A. 2011. Indicators of development as sexually selected traits: the developmental stress hypothesis in context. - Behav. Ecol. 22:1-9.

Thomas, R. J. 1999. The effect of variability in the food supply on the daily singing routines of European robins: a test of a stochastic dynamic programming model. - Anim. Behav. 57: 365-369.

Trivers, R. L. 1974. Parent-offspring conflict. - Am. Zool. 14:249-264.

Van Hout, J.-M., Pinxten, R. Geens, A. and Eens, M. 2012. Non-breeding song rate reflects nutritional condition rather than body condition. - PLoS One 7: e36547.

Zann, R. and Cash, E. 2008. Developmental stress impairs song complexity but not learning accuracy in non-domesticated zebra finches (Taeniopygia guttata). - Behav. Ecol. Sociobiol. 62:391-400. 


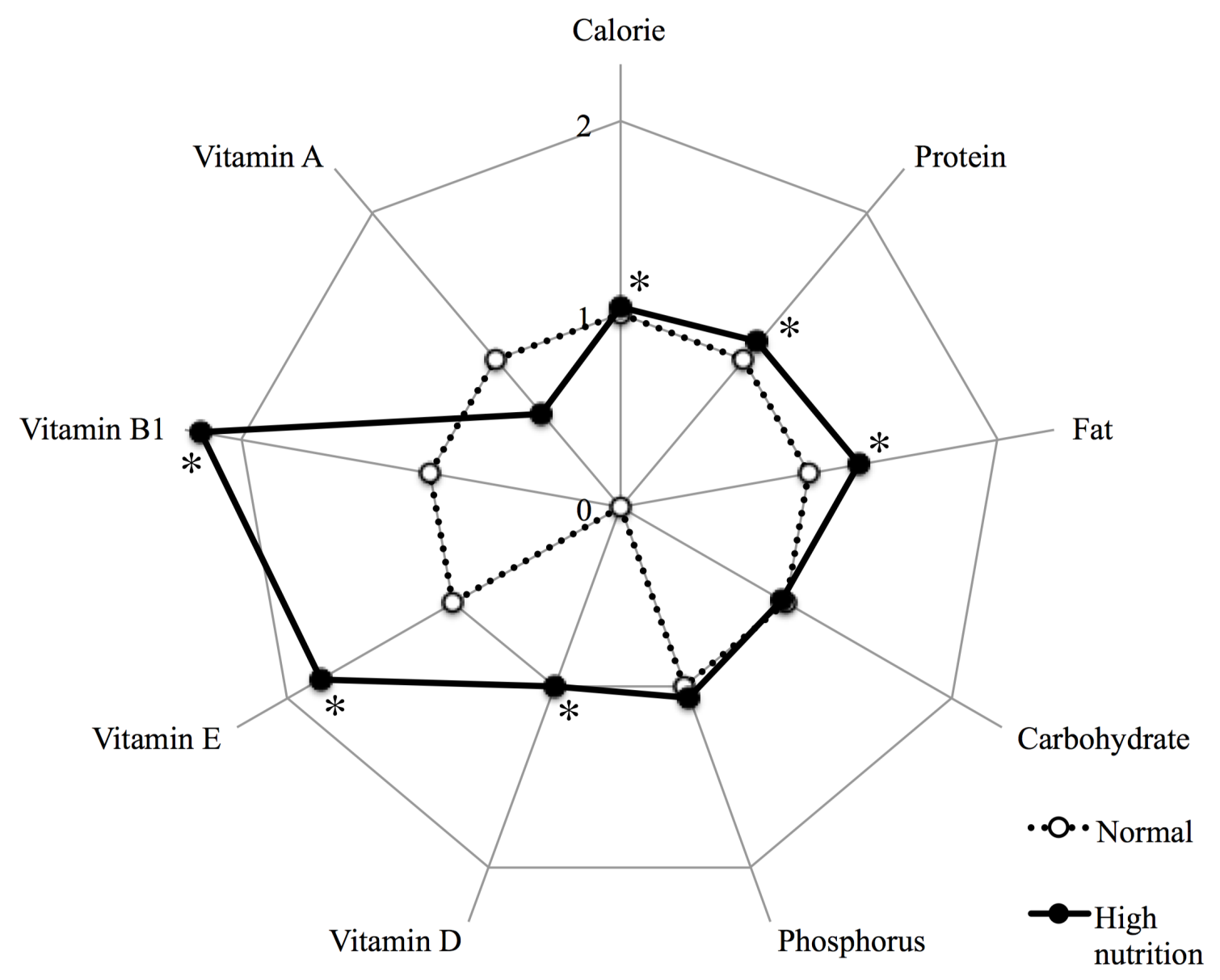

Figure 1. Estimated nutritional ingredients fed to control (open circles) and nutrition (fi lled circles) groups (see details in Supplementary material Appendix 1, Table A1, A2). Relative amount of each ingredient of the food consumed by the nutrition group was plotted with reference to that of normal food $(=1)$, except for vitamin $\mathrm{D}$, which was not included in normal food and shown as 0. ${ }^{*}: \mathrm{p}<0.05$ (Wilcoxon signed-rank test, Supplementary material Appendix 1, Table A2). 

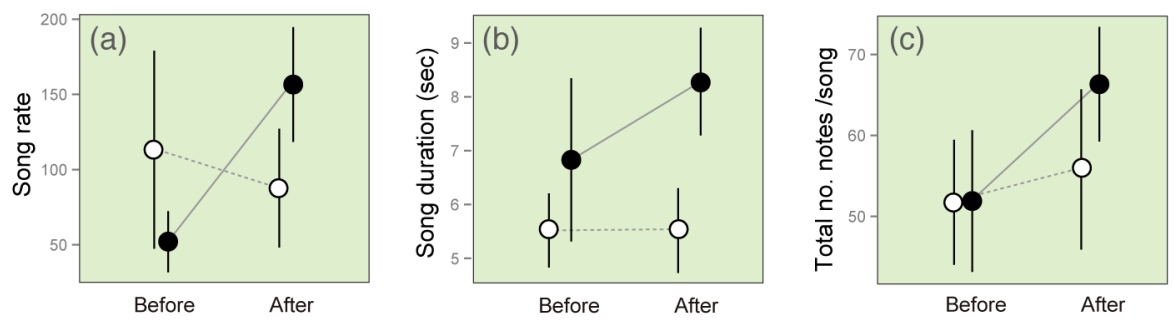

Vocal performance
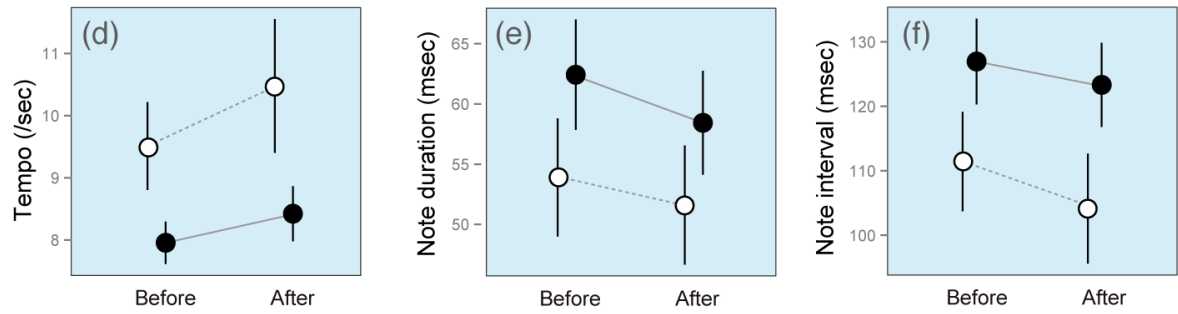

Song complexity
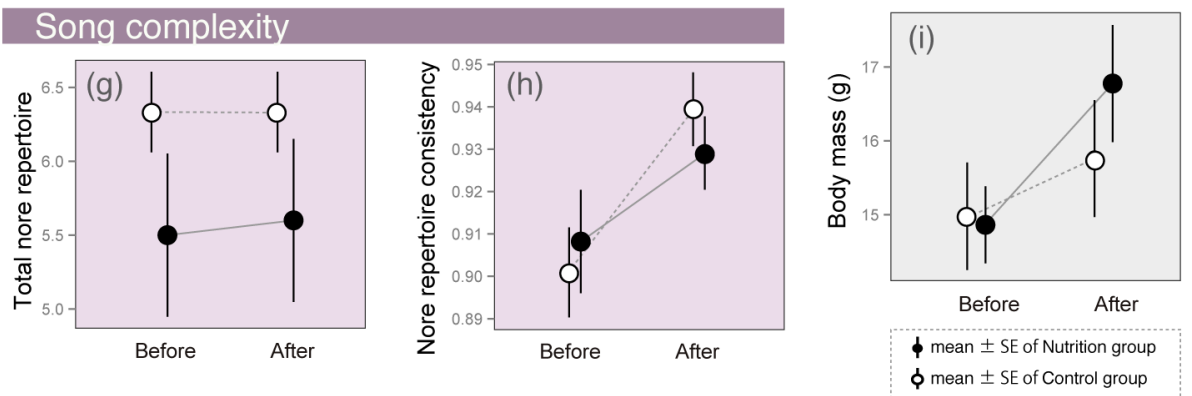

Figure 2. Changes in song output $(a-c)$, vocal performance $(d-f)$, song complexity $(g, h)$ and body mass (i) before and after the experimental period of nutrition and control groups (fi lled and open circles, respectively). 
Table 1. The effects of the experimental period and groups on song output (a-c), vocal performance (d-f), song complexity (g, h), and body mass (i). Positive values for the coefficients of experimental period and experimental group indicate that body mass or song variables increased after the period or in the nutrition group.

\begin{tabular}{|c|c|c|c|c|c|c|c|c|c|c|c|c|}
\hline & \multicolumn{12}{|c|}{ Song output } \\
\hline & \multicolumn{4}{|c|}{ (a) Song rate } & \multicolumn{4}{|c|}{ (b) Song duration (sec) } & \multicolumn{4}{|c|}{$\begin{array}{c}\text { (c) Total number of notes / } \\
\text { song }\end{array}$} \\
\hline & Coef. & SE & $z$ & $p$ & Coef. & SE & $t$ & $p$ & Coef. & SE & $z$ & $p$ \\
\hline Intercept & 3.23 & 0.6 & 5.9 & $<0.001$ & 5.96 & 0.92 & 6.5 & $<0.001$ & 3.95 & 0.13 & 29 & $<0.001$ \\
\hline Exp. period (Before / After) & -0.26 & 0.1 & 5.4 & $<0.001$ & 0.31 & 0.50 & 0.6 & 0.54 & 0.09 & 0.02 & 5.5 & $<0.001$ \\
\hline Group (Control / Nutrition) & 1.31 & 0.8 & 1.7 & 0.082 & 2.58 & 1.25 & 2.1 & 0.055 & 0.19 & 0.19 & 1.0 & 0.312 \\
\hline \multirow[t]{4}{*}{ After $\mathrm{x}$ Nutrition } & 1.36 & 0.1 & 20 & $<0.001$ & 1.42 & 0.71 & 2.0 & 0.045 & 0.16 & 0.02 & 7.1 & $<0.001$ \\
\hline & \multicolumn{12}{|c|}{ Vocal performance } \\
\hline & \multicolumn{4}{|c|}{ (d) Tempo } & \multicolumn{4}{|c|}{ (e) Note duration (msec) } & \multicolumn{4}{|c|}{ (f) Note-to-note inteval (msec) } \\
\hline & Coef. & SE & $t$ & $p$ & Coef. & SE & $t$ & $p$ & Coef. & $\mathrm{E}$ & $t$ & $p$ \\
\hline Intercept & 9.99 & 0.7 & 15.0 & $<0.001$ & 53.83 & 5.03 & 10.7 & $<0.001$ & 110.47 & 7.72 & 14 & $<0.001$ \\
\hline Exp. period (Before / After) & 0.38 & 0.1 & 4.4 & $<0.001$ & -1.91 & 0.60 & -3.2 & 0.001 & -3.60 & 1.15 & -3.1 & 0.002 \\
\hline Group (Control / Nutrition) & -1.65 & 0.9 & -1.8 & 0.215 & 7.80 & 6.94 & 1.1 & 0.378 & 15.67 & 10.66 & 1.5 & 0.280 \\
\hline \multirow[t]{4}{*}{ After $\mathrm{x}$ Nutrition } & -0.38 & 0.1 & -3.2 & 0.002 & -0.82 & 0.79 & -1.0 & 0.295 & 1.43 & 1.52 & 0.9 & 0.344 \\
\hline & \multicolumn{8}{|c|}{ Song complexity } & & & & \\
\hline & \multicolumn{4}{|c|}{ (g) Total note repertoir } & \multicolumn{4}{|c|}{ (h) Note repertoire consistency } & \multicolumn{4}{|c|}{ (i) Body mass (g) } \\
\hline & Coef. & $\mathrm{SE}$ & $z$ & $p$ & Coef. & SE & $t$ & $p$ & Coef. & SE & $t$ & $p$ \\
\hline Intercept & 1.85 & 0.13 & 13.9 & $<0.001$ & 0.88 & 0.03 & 28.0 & $<0.001$ & 15.76 & 0.78 & 20.3 & $<0.001$ \\
\hline Exp.period (Before/ After) & $<0.01$ & 0.19 & 0.0 & $>0.999$ & 0.02 & 0.01 & 2.0 & 0.042 & 0.78 & 0.44 & 1.8 & 0.917 \\
\hline Group (Control / Nutrition) & -0.12 & 0.19 & -0.7 & 0.513 & 0.03 & 0.04 & 0.8 & 0.515 & 1.02 & 1.07 & 1.0 & 0.442 \\
\hline After $\mathrm{x}$ Nutrition & 0.02 & 0.27 & -0.1 & 0.946 & -0.01 & 0.02 & -1.0 & 0.338 & 1.13 & 0.60 & 1.9 & 0.077 \\
\hline
\end{tabular}


Table S1. Ingredients of hand-made egg yolk-coated millet fed to the nutrition group.

\begin{tabular}{llrr}
\hline & Amount & & $\%$ \\
\hline Husked millet & & $800 \mathrm{~g}$ & 83.9 \\
Egg yolk & 4 & $72 \mathrm{~g}$ & 7.5 \\
Salt & 1 teaspoon & $6 \mathrm{~g}$ & 0.6 \\
TetraMin & 3 teaspoons & $5 \mathrm{~g}$ & 0.5 \\
Dried crucian powder & 9 teaspoons & $15 \mathrm{~g}$ & 1.6 \\
Honey & 20 cc & $28 \mathrm{~g}$ & 2.9 \\
Powdered milk & 9 teaspoons & $15 \mathrm{~g}$ & 1.6 \\
Soy bean flower & 2 teaspoons & $2.2 \mathrm{~g}$ & 0.2 \\
\hline
\end{tabular}




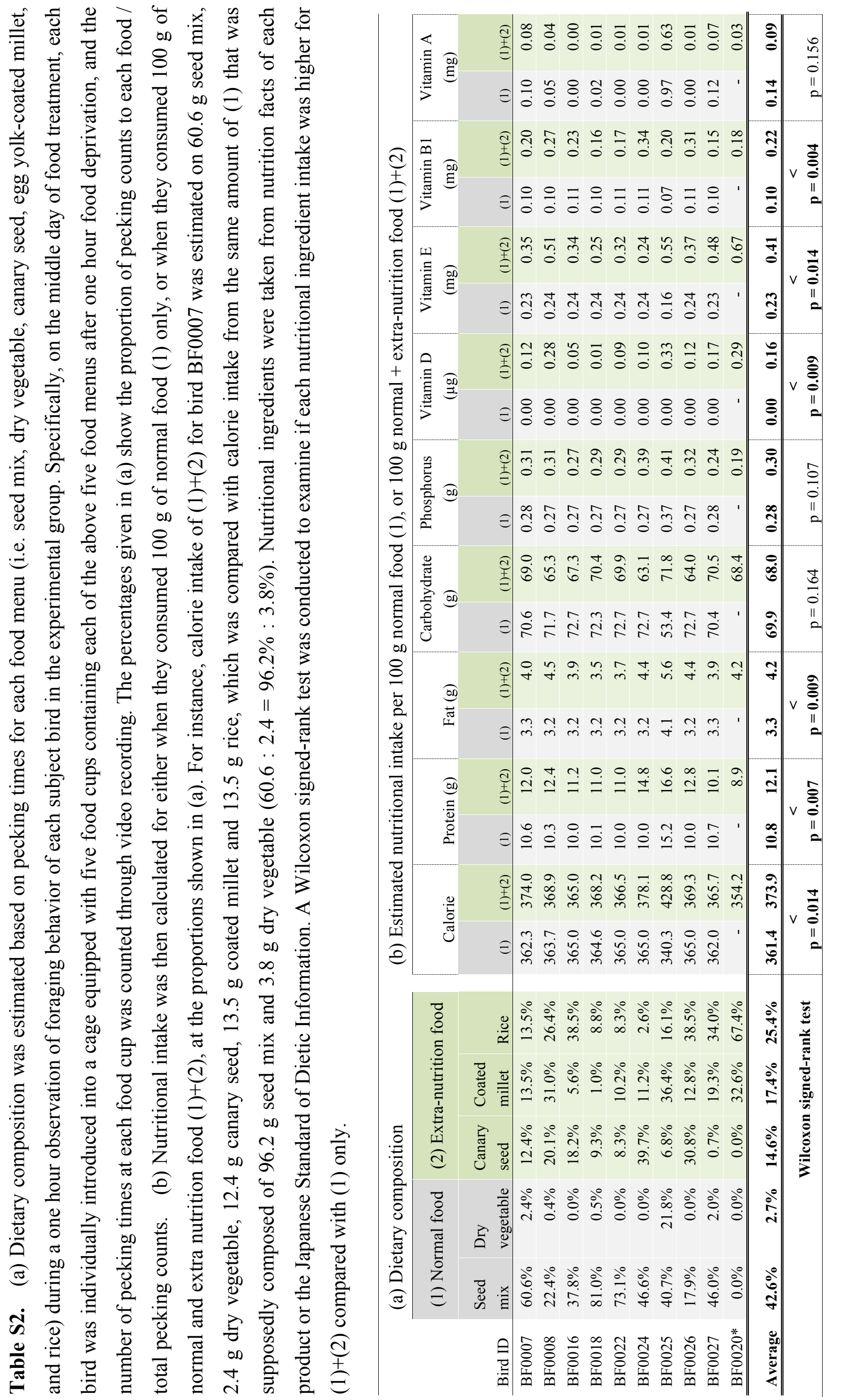

